\title{
Visual illusions and auditory hallucinations : scanning the neural correlates of perception
}

Citation for published version (APA):

Goebel, R. (2000). Visual illusions and auditory hallucinations : scanning the neural correlates of perception. Maastricht University. https://doi.org/10.26481/spe.20000101 rg

Document status and date:

Published: 01/01/2000

DOI:

$10.26481 / \mathrm{spe} .20000101 \mathrm{rg}$

Document Version:

Publisher's PDF, also known as Version of record

\section{Please check the document version of this publication:}

- A submitted manuscript is the version of the article upon submission and before peer-review. There can be important differences between the submitted version and the official published version of record.

People interested in the research are advised to contact the author for the final version of the publication, or visit the DOI to the publisher's website.

- The final author version and the galley proof are versions of the publication after peer review.

- The final published version features the final layout of the paper including the volume, issue and page numbers.

Link to publication

\footnotetext{
General rights rights.

- You may freely distribute the URL identifying the publication in the public portal. please follow below link for the End User Agreement:

www.umlib.nl/taverne-license

Take down policy

If you believe that this document breaches copyright please contact us at:

repository@maastrichtuniversity.nl

providing details and we will investigate your claim.
}

Copyright and moral rights for the publications made accessible in the public portal are retained by the authors and/or other copyright owners and it is a condition of accessing publications that users recognise and abide by the legal requirements associated with these

- Users may download and print one copy of any publication from the public portal for the purpose of private study or research.

- You may not further distribute the material or use it for any profit-making activity or commercial gain

If the publication is distributed under the terms of Article $25 \mathrm{fa}$ of the Dutch Copyright Act, indicated by the "Taverne" license above, 
Mijnheer de Rector Magnificus,

Leden van de Universitaire Gemeenschap,

Geachte collegae

Dames en heren,

Most of us take completely for granted our ability to see the world around us. How we do it seems no great mystery. When we open our eyes, we get excellent information about the environment experiencing a threedimensonal space filled with meaningful objects. We perceive all this so quickly and effortlessly that it is hard to imagine there being anything very complicated about it. Yet when viewed by biologists and psychologists as an phenomenon that must be explained, visual perception is so incredibly complex that it seems almost a miracle that we can do it at all. We get a hint that vision must involve many difficult computations by considering that despite extensive efforts, computer scientists have failed so far to build seeing robots which match even our most elementary visual abilities like recognizing a face.

\section{The constructive nature of vision}

To appreciate what the visual system is doing (Fig. 1), we must consider that vision begins with two-dimensional patterns of light falling on the retinas of our eyes. Millions of spatially arranged receptors transform the light photons into nerve signals which are sent to the brain for further processing. The initial retinal "raster images" include only bits and pieces of the objects being perceived. One major task of the visual system is to relate thousands of these little pieces to each other to determine which 
ones belong together forming potential objects. This process is also called "feature binding" and it is an important step for the proper segmentation of the visual input as well as the prerequisite for the recognition of potential objects. Considering that seeing starts with thousands of unrelated bits and pieces, we can describe it as follows: The visual system constantly tries to make sense out of the stream of changing light patterns falling on the retinas.

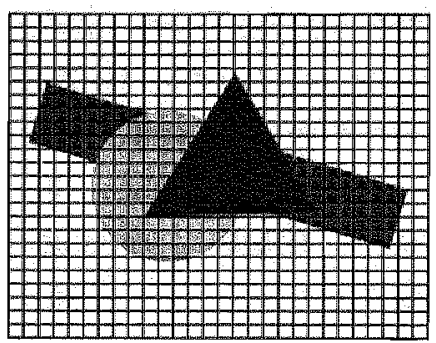

Retinal raster image
Physically presented contours
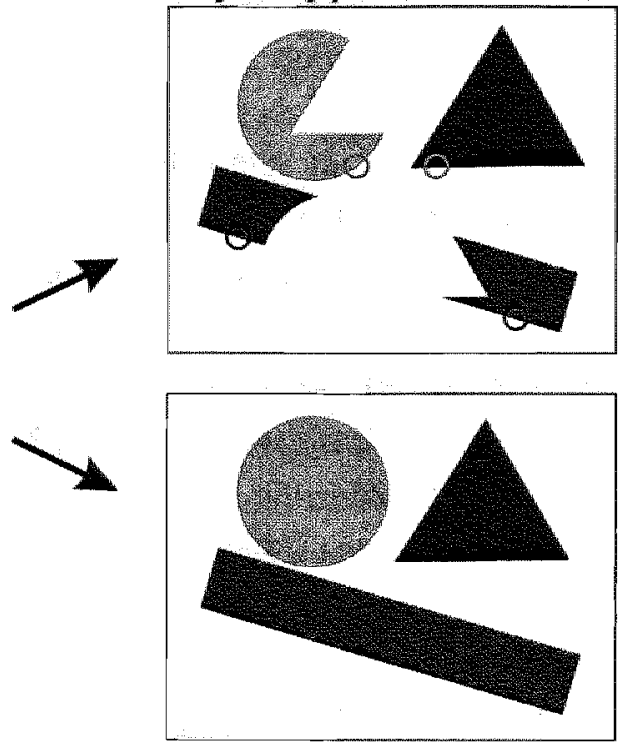

Perceived objects

Figure 1. Schema illustrating how the visual system "makes sense" out of retinal raster images. Locally detected pieces of information must be related with each other. We are aware only of the results of these processes: We perceive shapes even hardly noticing that we have completed the presented fragmentary contours. Note, that segments of the bar which are far apart from each other (dark circles) are "bound" together in the scene on the left side whereas segments close to each other (light circles) are assigned to two different objects. 
A bit more formally, I like to call this "making sense" principle the constructive nature of vision. The term "constructive" stresses that the visual input is not simply mapped onto the brain but is actively processed by numerous specialized cortical areas. We normally do not realize that there are these active processes because our consciousness reflects only their outcome - objects in 3D space. We get, however, a glimpse of their working when experiencing visual illusions. Figure 2B, for example, shows the famous Kanizsa triangle. As shown in figure $2 \mathrm{~A}$, only three open disks or "pacmen" are physically presented but if they are positioned appropriately, our visual system relates the individual pacmen with each other by "inventing" a triangle with illusory contours that do not physically exist. The visual system, thus, goes beyond the mere physical properties and this is it what I refer to as "constructive processes".
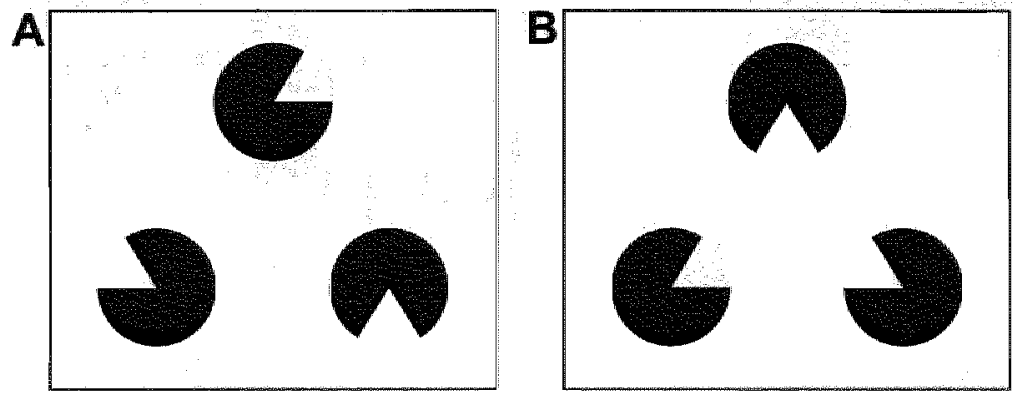

Figure 2. The Kanizsa triangle (B) is a fascinating illustration that the brain relates pieces of information with each other. The same three partial circles are shown in A) and B) but only in B) the brain "constructs" a triangle with illusory contours that do not actually exist in the stimulus image. 


\section{The visual system}

How does the brain perform the illustrated visual computations? A large portion of my research aims at contributing to answer this question using modern brain imaging techniques. A lot is already known about the visual system both from animal and human studies.

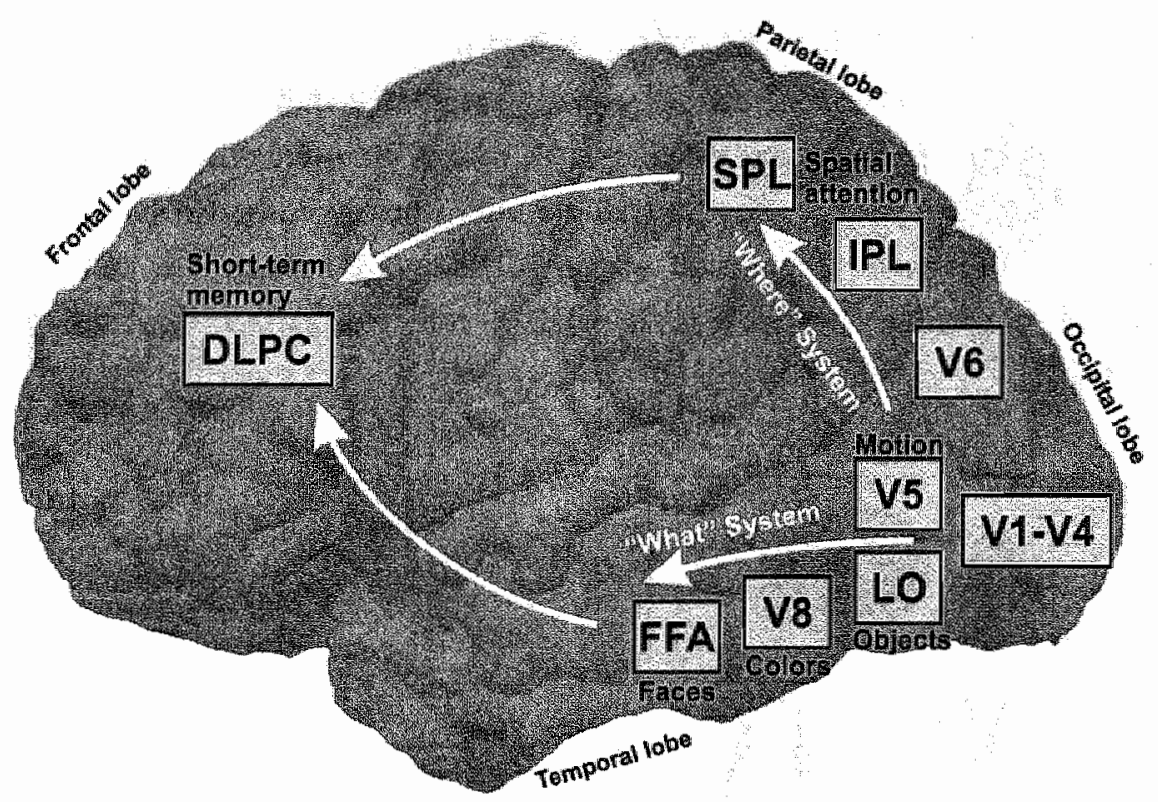

Figure 3. Schematic diagram of the visual pathways based on human imaging studies. Despite oversimplifications, the diagram illustrates the dorsal stream or "where" system and the ventral stream or "what" system as well as functional specializations of visual areas. $L O=$ lateral occipital complex, FFA $=$ fusiform face area, $\mathrm{IPL}=$ inferior parietal lobe, $\mathrm{SPL}=$ superior parietal lobe, $\mathrm{DLPC}=$ dorso-laterăl prefrontal cortex. 
The visual information of the retinas reaches the cortex in the occipital lobe, more precisely in the primary visual cortex also called area VI. Much experimental evidence has supported the existence of two main visual pathways in the primate cortex (Ungerleider \& Mishkin, 1982); a ventral stream or "what": system devoted to the fine-grained analysis of the visual scene, including the perception of form and collour, and a dorsal stream or "where" system which processes spatial characteristics of the visual scene and analyzes motion. These pathways emerge in area V1/V2 and project into the temporal lobe (the "what" stream) and into the parietal lobe (the "where" stream). Monkey studies have revealed that these two systems consist of more then 30 highly interconnected, specialized areas (for a review: see Fellemann \& Van Essen, 1992). The areas appear to be organized in a hierarchy consisting of at least 10 cortical stages. With brain imaging techniques it has been shown that the "where" and the "what" systems exist in man as well. Figure 3 depicts a highly simplified diagram of the organization of the visual system based on human imaging studies. To construct a complete representation of a visual percept, the areas of the two streams must also interact with each other to some extent. Some of the fMRI studies reported below investigate interactions of areas within and between the "where" and the "what" system.

\section{Principles of fMRI}

Functional magnetic resonance imaging (fMRI) is a new application of nuclear magnetic resonance that allows us to study non-invasively not only the structure (anatomy) of the brain, but also its function (physiology). In other words, with fMRI it is possible to study not only what the brain looks like, but also how the brain works when a subject in 
the scanner is looking at images, listening to sounds, imagining something or recollecting prior experiences.

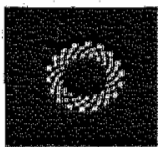

Stimulus

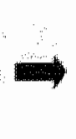

Neural pathway

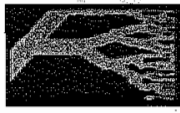

Hemodynamics

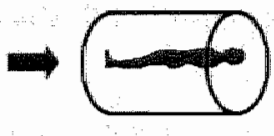

MR sicanner

Figure 4. From stimulus to fMRI signal. With functional MRI, the neural signal cannot be measured directly. The measured indirect vascular signal - the hemodynamic response - is, however, tightly coupled to neuronal events.

How is this possible? When the neuronal activity in a brain area increases, that area consumes more energy. The neuronal tissue gets its energy from oxygenated hemoglobin in the blood. Within a few seconds the blood flow and the concentration of oxygenated hemoglobin in the blood increases in that area, this is called the hemodynamic response. This response can be measured in the scanner because oxygenated hemoglobin produces a special magnetic signal. Since fMRI detects changes in the concentration of oxygenated hemoglobin, the measured signal is also called BOLD response (blood oxygenation leveldependent).

\section{FMRI studies of perception}

In the following, I will report about several fMRI studies which I have done with my colleagues to unravel the neural substrate of visual and auditory perception. Most of our studies focus on the "where" system using moving stimuli including apparent (illusory) motion and mental imagery of motion stimuli. These and further experiments lead to 
interesting insights about constructive brain processes. We also perform so called retinotopic mapping studies with most of the subjects. This allows us to separate adjacent early visual areas from each other. Anatomical and functional data analysis of all experiments was performed with our "BrainVoyager" software package (see http://www.BrainVoyager.com).

\subsection{Retinotopic mapping}

The good spatial resolution of fMRI allows us to measure the retinotopic organization of early visual areas in individual subjects (Sereno et al., 1995; Goebel et al., 1998; Linden et al., 1998). The "retinal raster images" mentioned earlier project to the primary visual cortex in an orderly manner retaining the two-dimensional spatial layout. When a visual stimulus covering only part of the visual field is presented, a corresponding piece within primary visual cortex will be activated. By letting such a stimulus "scan" the whole visual field, e.g. by rotating a pie-like stimulus around the center of gaze, a complete spatial "map" can be reconstructed in V1 as well as in secondary visual areas like V2, V3/VP and V4 (Fig. 5). The results of these experiments are best visualized on unfolded representations of the cortex instead of a set of slices because "inflated" or "flattened" representations (Fig. 5) utilize the intrinsic topology of the cortex. The cortex is a two-dimensional sheet which is highly folded to fit in the limited space of our heads. The exact folding pattern differs between individuals so that each of us has its own characteristic pattern of gyri and sulci. The results of retinotopic mapping studies are interesting per se but they also form the basis for a detailed analysis of complex cognitive functions like visual attention or visual imagery (see section 4.4). 

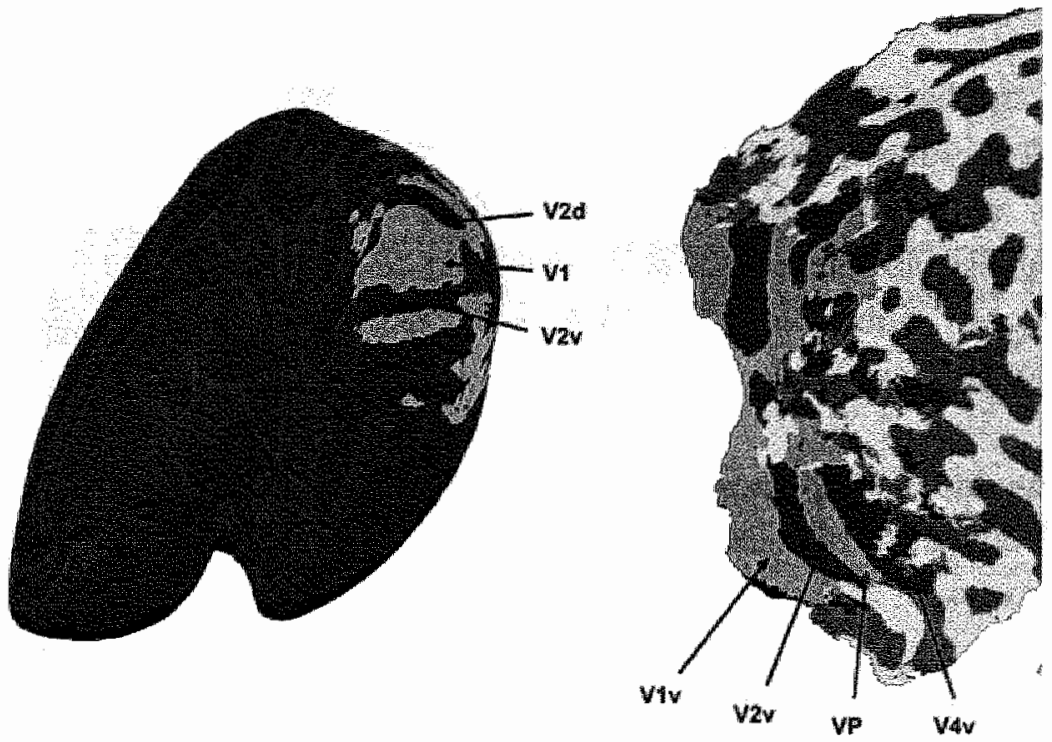

Figure 5. Functionally defined boundaries of early wisual areas as the result of retinotopic mapping experiments. The cortical areas are visualized on an inflated hemisphere (left) and on a flat map of the occipital lobe (right). The right hemisphere shown represents the left visual field which again is represented in two halves: The left upper quadrant of the visual field is mapped to the right lower ("ventral") part of the hemisphere and the left lower quadrant is mapped to the right upper ("dorsal") part. The shading outside of the mapped areas visualize the folding of the cortex with darker shaded regions corresponding to sulci and brighter shaded regions to gyri.

\subsection{Illusory contours and apparent motion}

Perceptual illusions are important tools in the experimental study of constructive aspects of vision. Certain types of illusions arise when the brain uses a priori assumptions about the world to infer properties of perceived objects that are presently not available to the senses. For example, when stimuli separated in space are turned on and off in 
alternation at appropriate temporal intervals (Kolers, 1972), subjects perceive one stimulus moving between the two stimulus positions rather than two stationary flickering stimuli. The perception of motion of objects that in fact do not change position is an example of a constructive visual process and is called apparent motion.
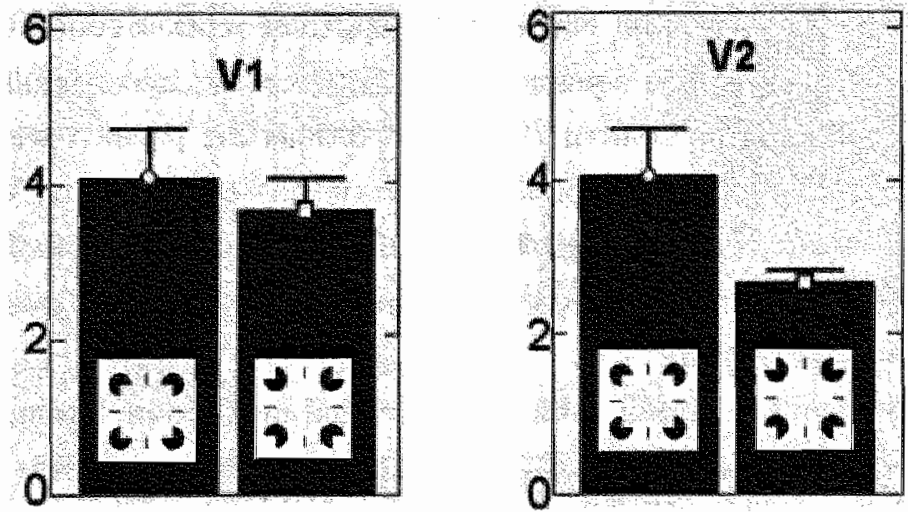

Figure 6. Activity to illusory contours in areas $\mathrm{V} 1$ and $\mathrm{V} 2$ for a group of 8 subjects. The activation difference is much higher in V2 than in V1.

We combined the perceptual illusion of apparent motion with a second illusion by using squares whose outlines consisted of subjective contours (Goebel et al., 1998). Our stimulus induces a percept where an illusory square performs an illusory motion. The illusory squares were presented in alternation on the left and right side of the fixation spot (Fig. 7, left). In order to generate the percept of an appearing and disappearing square, the four "pacmen" defining a square were opened and closed simultaneously so that observers saw either a Kanizsa square or four filled circles at the respective location. In the control condition without motion cues, the 
illusory Kanizsa squares appeared and disappeared simultaneously on both sides of the fixation cross whereas in the apparent motion condition they appeared and disappeared in alternation (Fig. 7, left). There was a difference in relative timing between the hemifields, but stimulation conditions within each hemifield remained the same in both conditions. In the control condition subjects reported seeing two squares appearing and disappearing in alternation while in the apparent motion condition they reported seeing a single square moving between the two stimulus locations. In additional no-contour control conditions the pacmen were opened outward and thus did not produce illusory squares. Only area V2 showed a much stronger response to the conditions with illusory contours as compared to the control condition suggesting that this area constructs the illusory contours (Fig. 6).

Despite nearly identical stimuli, area V5 responded much more strongly during apparent motion than during the control stimulus which is perceived as two blinking squares (Fig. 7). Our results suggest that area V5 is the first cortical area along the dorsal stream that is capable of extracting apparent motion cues: In contrast to V1, V2 and V3, its responses differed significantly between the apparent motion conditions and the respective flickering controls. The comparison of responses to illusory-contour and no-contour conditions suggests that area V5 is also capable of using illusory contour information for computing and representing apparent motion. Area $\mathrm{V} 2$ responded more strongly to the illusory-contour conditions than to the matched no-contour conditions suggesting that the illusory contour information is extracted at that level and made available as input to area V5. That V5 appears to be critical for representing moving stimuli is corroborated by reports about bilateral lesions that include this area causing cerebral akinetopsia, the inability to 
perceive motion. In conclusion, it appears that the activity state of area V5 correlates with the conscious percept of the observer and not with the physical stimulus properties.
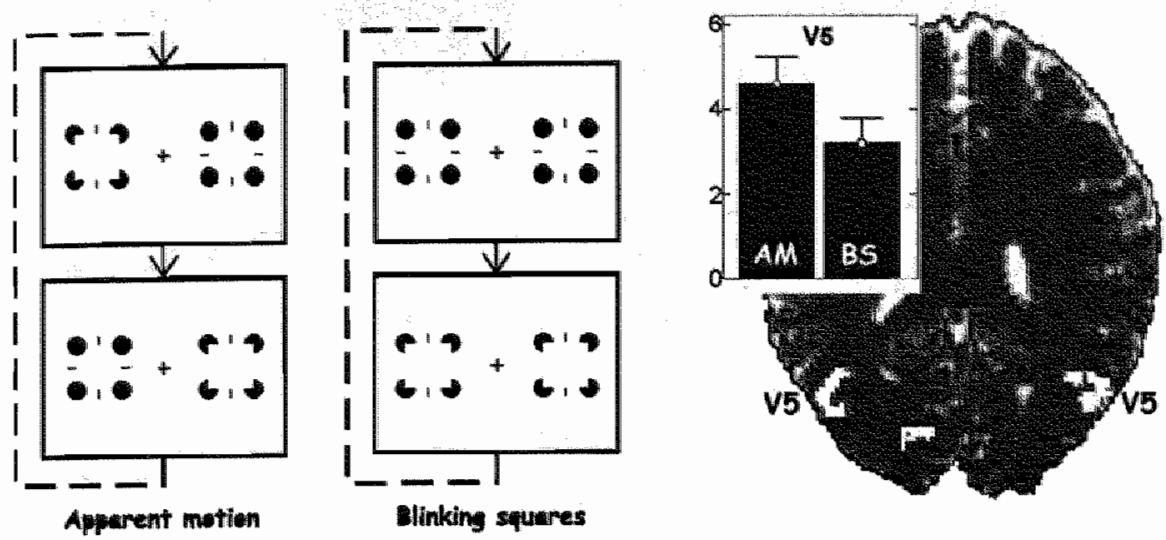

Figure 7. Stimuli and results of the apparent motion experiment. Subtracting the "blinking squares" condition (BS) from the "apparent motion" condition (AM) revealed significant activity in area V5 shown in white color superimposed on a functional EPI slice of subject MC and quantified across 7 subjects in the inset.

\subsection{Head-from-motion}

One paradigm particularly interesting for studying constructive brain processes is the perceptual phenomenon of three-dimensional structure from motion (SFM) in which a small number of moving dots induces the perception of a 3D object. Since the motion of dots is assumed to be processed in the "where" system but the perceived objects are assumed to be represented in the "what" system, the SFM paradigm is especially well suited to study the interaction between the two main processing streams. 


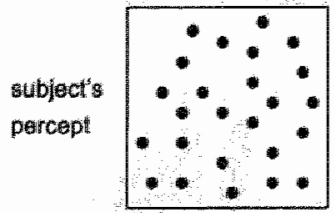

Sto

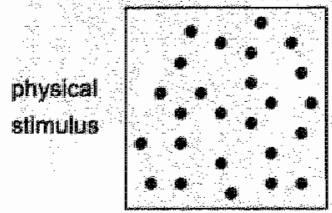

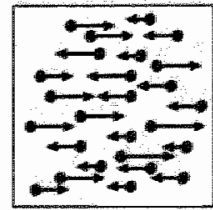

Mollon contioit

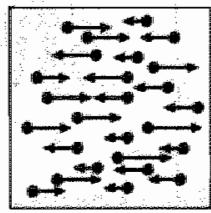

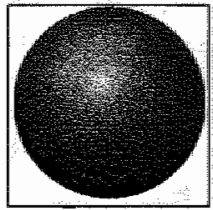

OFWI I INWHFM

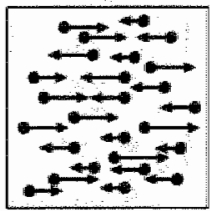

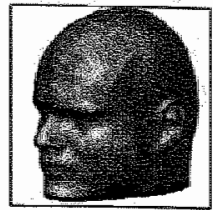

$3 D$ HFM

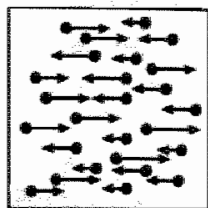

Figure 8. Stimuli of the shape-from-motion experiment. Although the three conditions with moving dots contained identical motion vectors concerning dot number, direction and speed (shown in the second row), the observer experiences clearly different percepts as indicated in the first row. The three motion conditions differ in the spatial arrangement of the motion vectors inducing either OFM (object-from-motion), HFM (head-from-motion), invHFM (inverted headfrom-motion) or no perception of a $3 \mathrm{D}$ object (motion control).

In our study (Naumer et al., 2000; Goebel et al., 2000) we addressed the question to what extent areas in the ventral stream respond to a small number of moving dots and whether areas specialized for different object categories respond selectively to different SFM stimuli. In our main condition, the moving dots were arranged in such a way that the observers vividly experienced a $3 \mathrm{D}$ rotating head. We named this stimulus "3D head-from-motion" or HFM. This condition was contrasted with a SFM condition inducing the percept of simple objects (spheres and boxes) which we called "3D object-from-motion" or OFM. The full experiment consisted of five different stimulus categories (Fig. 8): 1) 
stationary dots, 2) motion control, 3) OFM, 4) HFM with inverted headis and 5) HFM. In the motion control condition, the same motion vectors (directions and velocities) as in the OFM/HFM conditions were presented but in different spatial arrangements which are not perceived as threedimensional objects.

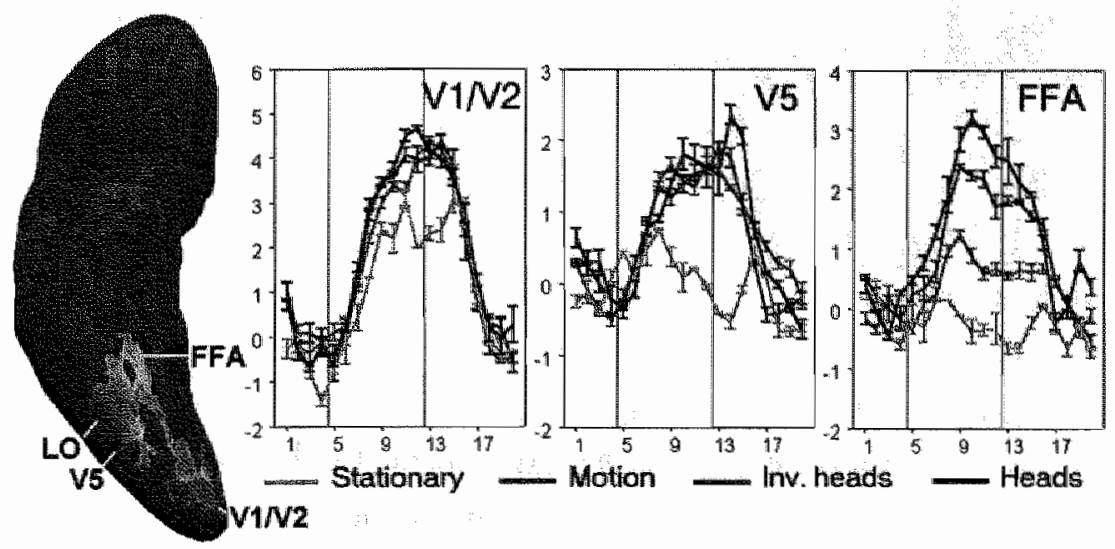

Figure 9. Results of the structure-from-motion experiment of subject RG. Response selectivity is highest in the fusiform face area (FFA).

The results of eight subjects showed that areas V1/V2 were activated to a similar extent by all stimulus categories. Since responses in early visual areas are determined to a large extent by physical stimulus properties, this result indicates that the different motion conditions are indeed matched appropriately. The main finding was an increasing stimulus selectivity as one moves from V1/V2 to V5, LO and the anterior fusiform gyrus (FG). Area V5 was similarly activated by all experimental conditions containing moving stimuli and only little by the stationary stimulus. Area LO responded with equal magnitude to the OFM and HFM conditions but 
much less to the motion control condition. Finally, a region in the anterior fusiform gyrus showed a significantly higher response during HFM than during OFM. This most selective region turned out to be the fusiform face area (FFA, Kanwisher et all, 1997) which is known to respond best to faces. In summary, the results help localize constructive brain processes by showing that a small number of appropriately moving dots is sufficient to differentially activate highly specialized areas in the ventral processing stream.

\subsection{Motion imagery}

Visual imagery may be performed in the complete absence of visual stimuli. Thus, when a subject is asked to imagine a previously seen visual scene, the task usually consists in the construction of a visual image purely from stored information. In our experiment (Goebel et al., 1998), subjects imagined seeing moving objects. After they had seen one of three motion stimuli for 24 seconds (radially moving dots, apparent motion or a rotating grating), they were required to fixate a cross for 24 seconds. This long interval was introduced in order for the hemodynamic response to return to baseline level before the start of the following imagery condition. After this fixation period, the fixation cross was turned off briefly, which signalled to the subject that they should now try to imagine the previous motion stimulus as intensely as possible while fixating the cross. After 24 seconds, the end of the imagery condition was signalled to the subject by shortly turning off the fixation cross once more. All subjects reported that they were able to mentally evoke a clear motion experience during the imagery periods. 


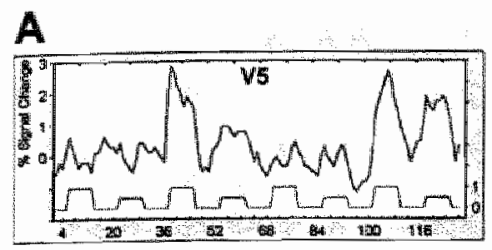

$s$ sI H M $s$ si $M$ MI

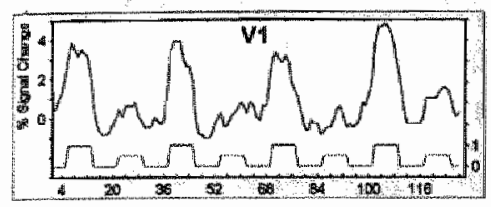

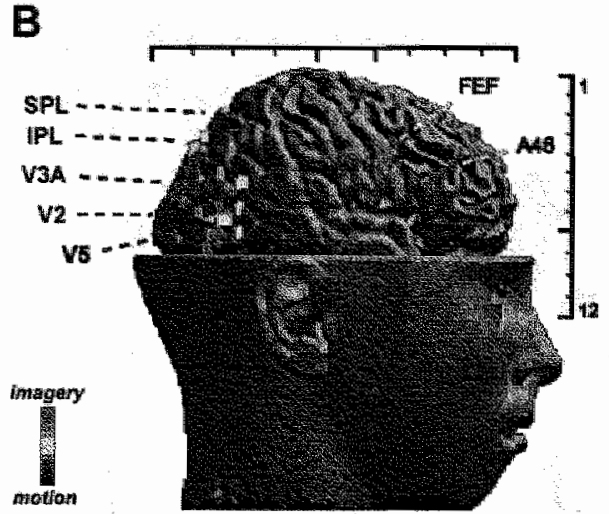

Figure 10. Results of the motion imagery experiment for subject CG. The imagery related activity roughly increased with the distance of an area from V1. In subject $\mathrm{CG}$, area V5 and a region in the IPL responded as strongly during motion imagery as during visual perception of real motion (white colored regions depicted on the brain). Area V5 selectively responded only during intagery of moving objects (MI) but not during imagery of stationary objects (SI) while area V1 responded to stationary (S) and moving stimulli (M) but only weakly during imagery episodes (SI, MI).

As expected, early areas and V5 responded to the initial presentation of real and apparent motion stimuli. However, most of these areas also showed a surprisingly high activation during motion imagery. Interestingly, the imagery specific activation increased with the synaptic distance of an area from V1 along the dorsal processing stream (Fig. 10). Area V5 was activated approximately half as much during imagery conditions as in the motion conditions. 


\title{
4.5 Auditory hallucinations
}

\author{
"Something is seen, heard, \\ smelled, tasted, felt on or in the body, but \\ objectively -from the extemal observer's \\ point of view - it is not present." \\ K. Schneider, 1962
}

Another example of a constructive process is the phenomenon of hallucination. We conducted a study with schizophrenic patients suffering from auditory hallucinations (Dierks et a1., 1999) in collaboration with the department of Psychiatry of the "Johann Wolfgang Goethe" Universitåt in Frankfurt/Main, Germany. Hallucinations are perceptions that appear completely real to the perceiver although there is no corresponding external sensory stimulus. They are the most common symptom of schizophrenia, being reported by about $65 \%$ of the patients. The patient does not just hear sounds but fully formed verbal communications that appear to emanate from a particular speaker or group of speakers. These imaginary speakers often seem capable of reading the patient's thoughts and are usually perceived as hostile. Hallucinations can cause considerable distress, for example when the voices continually criticize the patient and command the patient to act against his or her wishes. In this study we asked the question: How can it be that, in the absence of any sound, the hallucinating patients experience these voices as real?

When hearing voices, music or any type of sound, the signall at the ears is converted into a series of electrical impulses by many internal organs. These impulses are then transferred to the areas of the brain that analyze the sounds and make them understandable. The earliest cortical auditory 
area is called the primary auditory cortex or Al much like VI refers to the earliest visual area of the cortex.
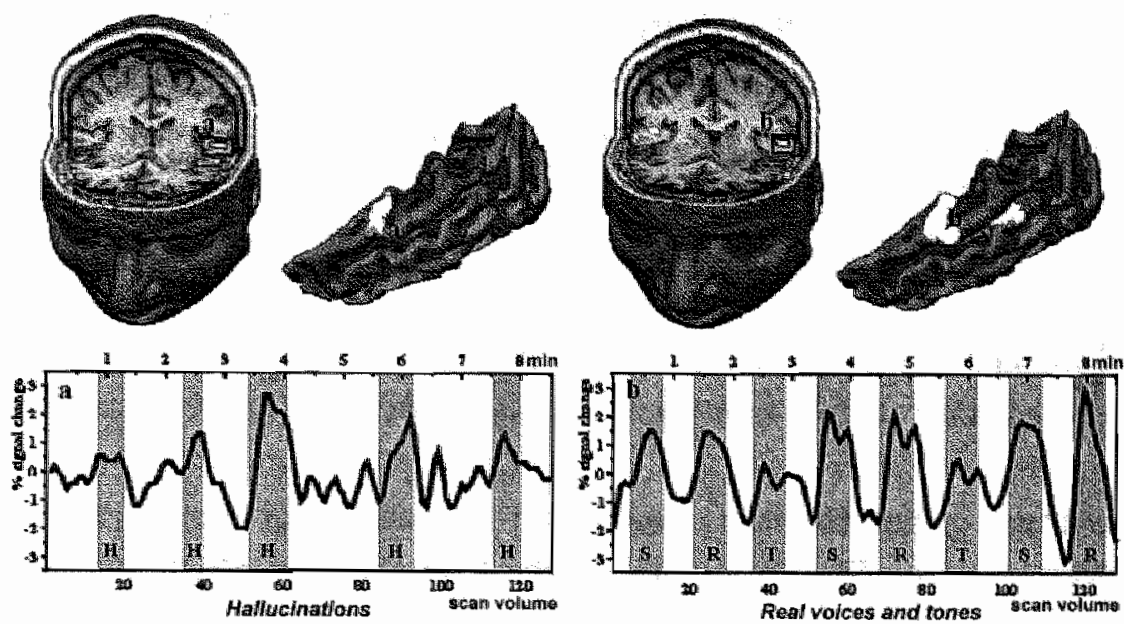

Figure 11. Activation of Heschl's gyrus during auditory hallucinations. Location of activity in Heschl's gyrus (early auditory areas) is shown on a slice view and a rendered view of the temporal lobe in the upper panells; the observed time courses in Heschl's gyrus are shown in the lower panels. The right side shows the result after presenting real voices (S), reversely played voices (R) and tones (T), the left side shows the result during hallucinatory episodes $(H)$.

When the patients or normal subjects heard voices via headphones in the scanner, primary auditory cortex was indeed found to be highly activated (Fig. 11, right). In contrast, when patients or normal subjects were instructed to imagine voices, primary auditory cortex was not found to be activated. In the main experiment, no voices were played through the headphones but the patients were instructed to press a button whenever they heard voices and release the button when they did not hear them. We 
compared activity between phases with and without hallucinations, reasoning that areas more active during the hallucinations might be involved in their constructions. We were surprised to find that auditory hallucinations, in contrast to mere imagination of voices, activated primary auditory cortex as strongly as real voices did (Fig. 11, left). This means that the voices internally generated by the patients during the hallucinations produce effects on the brain that are indistiguishable from those generated by an external voice. This might explain why hallucinations, unlike auditory imagery or inner speech, are experienced as reall.

\section{The future of cognitive neuroimaging}

After having presented a few studies illustrating the current possibilities of fMRI, I finally want to share with you my vision about the future of cognitive neuroimaging.

5.1 Computational neuroimaging. I think it is important to realize that fMRI is not only useful to "map" brain areas but also to investigate how the strength of activity within an area changes with respect to subtle changes in the stimulus or internal state of a subject. In my opinion, this aspect is largely underestimated but offers the possibility of computational neuroimaging (Wandell, 1999) allowing to study cognitive processes in much greater detail than was expected previously. Recently obtained data from animal studies recording the fMRI signal and electrophysiological signals from neurons simultaneously justify this approach by showing a strong quantitative relationship between the strength of neural activity and the strength of the vascular fMRI signal 
(Logothetis et al., 2000). A computational approach will provide important constraints for building neural network models relating local neuronal processes to the more global fMRI and EEG/MEG signals. In my view, large-scale neural network models provide an appropriate language for formulating detailed "dynamic" theories of brain function as a means to answer not only the "where" question but also the "how" question.

5.2 Combining fMRI and MEG/EEG. Despite the evidence that the indirect measure of neural activity that fMRI provides is quite precise, it is also clear that the indirectness is the weakness of this method when it comes to temporal resolution. It is, thus, desirable to combine fMRI with techniques providing temporal resolution in the millisecond range like electro- and magnetoencephalography (EEG, MEG). There are still many problems to solve but this combination of methods will allow noninvasive measurement of both the topographic distribution and the precise timing of neuronal processes in humans.

5.3 Columnar-level fMRI. One of my scientific dreams is to achieve a columnar-level resolution with fMRI in a robust and reliable way. Cortical columns contain several thousand neurons specialized roughly for the same (micro-)feature. These columns appear to be at the right level of organization for studying the working brain in sufficient detail without getting lost within a network of 10 billion neurons. A columnarlevel resolution would allow us to study neuronal codes or "assemblies" within areas and how they are mapped and transformed in other areas. Cortical column resolution fMRI has recently been demonstrated in 
animal studies (Kim et al., 2000) and I expect that it will be achieved soon in humans - at least in scanners with high magnetic fields.

\subsection{Noninvasive measurement of anatomical connectivity. The} noninvasive measurement of anatomical connectivity has become feasible recently with an MRI technique called diffusion tensor imaging (DTI). With this technique it becomes possible to combine the mapping of functional activity with the mapping of anatomical connectivity for the same human brain. We are currently developing tools to extract and visualize the fibres connecting brain areas. With this technique, we will not only' see which areas are activated in a given task but also whether areas are connected directly or indirectly with each other. This will open new frontiers for basic research in cognitive neuroscience as well as for a range of medical applications, like schizophrenia, Alzheimer disease and developmental dyslexia, in which connectivity problems seem indicated.

5.5 Real-time fMRI. Since fMRI data analysis is computationally very intensive, it is normally performed after a scanning session. In contrast, real-time fMRI lets researchers observe the working brain alleady during the measurement allowing them to judge whether the ongoing measurement works satisfactorily. Real-time fMRI has recentlly become possible using fast computers and incremental statistical computations. I developed a new method called "cortex-based real-time fMRI" which is better suited for certain applications like biofeedback than previous approaches. The new method will be used for helping so called "lockedin" patients studied by Prof. Niels Birbaumer (Tiubingen, Germany). These patients are completely unable to move their body. They can slowly learn to communicate via EEG signals. Since fMRI is spatially 
more specific and requires less temporal averaging to reliably detect responses, our new real-time fMRI tools might allow them to learn voluntary control of their brain activity more effectively.

I hope that my research and technical developments will lead to a better understanding of the human brain as well as to new clinical applications.

\section{Personal words and acknowledgement}

At the end of my talk, I would like to thank all those people who supported me in the past and made it possible that I am now standing here.

I want to say a special thank to the rector magnificus, the College van Bestuur and the College van Decanen of the Universiteit Maastricht for opening up for me the chair in Cognitive Neuroscience in the faculteit der Psychologie.

I am deeply grateful to our dean, Gerjo Kok, and our director Ed Sprokkel for providing us with excellent research and teaching conditions in our nice psychology building. I also want to thank Anouk, Annemarie and all other helpful people in the levels 3 to 5 of UNS 40 .

I also want to thank the rector magnificus, Peter Tindemans, Jos van Engelshoven, Leo Blomert and our belgian colleagues Emile Beuls and Jan Gelan for their great support in establishing a promising program within the transnationale Universiteit Limburg (TUL). Among other important research directions, the TUL will very likely allow us to pursue 
our neuroimaging research in Maastricht on a high-performance 3 Tesla scanner. With this facility we can continue our methods development at the highest level contributing to the international frontier position of the TUL.

I also want to thank Peter Hagoort and Pim Levelt for giving me the opportunity to be a research fellow in the F.C. Donders Centre for Cognitive Neuroimaging in Nijmegen and I want to thank our university for financially supporting this centre which allows us to conduct there combined fMRI and MEG/EEG studies in the coming years.

I am deeply grateful to my colleague and new friend Leo Blomert. I enjoyed our successful teamwork for the Breedte strategy and the TUL among others and I am looking forward to our future scientific collaboration.

I want to say a very special thank to Dirk Vorberg who truly set the course for my scientific career when I was a student. I owe my enthusiasm for cognitive psychology to him and I am very glad that I had him as a mentor in the past and to know him now as a colleague and friend.

I am deeply grateful to Wolf Singer who strongly influenced my scientific career when I was a researcher. I deeply admire him as a truly great scientist and I am impressed about his liberal and far-sighted syle of guidance. He brought me together with Hans Hacker who generously allowed me to use his MR scanner which was the start of my fMRI career. It was also Wolf Singer who brought me together with Michael 
Scherg which was the start of a fruitful collaboration on combining AMRI and MEG. I also want to thank Lars Muckli, David Linden, Matthias Munk, Andreas Engel, Ralf Galluske, Kerstin Schmidt, Pieter Roelfsema and Sergio Neuenschwander for their friendship and excellent scientific work at the Max-Planck-Institute in Frankfurt.

I want to thank my colleague and friend Michael Scherg for an extremely fruitful collaboration and for the many things I have learned from him about MEG data analysis.

I am very grateful to thank Hans Hacker, Friedhelm Zanella and Jos van Engelshoven for providing access to their MR scanners.

I also want to thank Francesco diSalle, Thomas Dierks, Pascal Fries, Petra Stoerig, Dae-Shik Kim, Steffen Egner, Brian Wandell and other colleagues for very fruitful and enjoyable collaborations.

I want to say a very special thank to Bernadette Schmitt informing me about the cognitive neuroscience professorship in Maastricht.

I want to say a very special thank to all members of my former group in Frankfurt and my new group in Maastricht, especially Lars Muckli, David Linden, Elia Formisano, Miguel Castelo-Branco and Niko Kriegeskorte. I feel extremely lucky that I can work with such talented people and I am glad to know them as true friends I always can count on.

It is a great pleasure to thank Claudia, Henk Jansma, Armin Heineke, Walt Schneider and colleagues from PST and MRI Devices for their great 
work on helping me to make BrainVoyager an increasinglly powerful and successful software package.

I am very glad that my parents, Helga and Wilhelm Goebel, my sister Jutta with her family and my brothers Gebhard and Peter as well as my parents-in-law Christa and Bernd Böcker are here today. I am deeply grateful for having this great family which equipped me with the necessary emotional and intellectual skills for my life.

Last but not least I cordially thank my beloved wife Claudia, the true source of strength in my life.

Mijnheer de Rector,

Dames en Heren,

Ik heb gezegd. 


\section{References}

Dierks, T., Linden, D.E.J., Jandl, M., Formisano, E., Goebel, R., Lanfermann, H., Singer,W. (1999). Activation of Heschl's gyrus during auditory hallucinations. Neuron, 22, 615-621.

Fellemann, D.J. \& Van Essen, D.C. (1992). Distributed hierarchical processing in the primate cerebral cortex. Cerebral Cortex, 1(1), 1-47.

Goebel, R., Naumer, M.J., Muckli, L., van Mier, H., Engel, A.K., Zanella, F.E. and Singer, W. (2000), Structure-from-motion of threedimensional objects differentially activates specialized areas in the ventral processing stream. Soc Neurosc. Abstr.

Goebell, R., Khorram-Sefat, D., Muckli, L., Hacker, H. and Singer, W. (1998) The constructive nature of vision: Direct evidence from fMRI studies of apparent motion and motion imagery. The European Journal of Neuroscience, 10, 1563-1573.

Kanwisher, N, McDermott, J, Chun, MM (1997). The fusiform face area: a module in human extrastriate cortex specialized for face perception. $J$ Neurosci, 17(11), 4302-11.

Kim, D.-S. Duong, T.Q., \& S.-G. Kim (2000) High-resolution mapping of iso-orientation columns by fMRI. Nature Neurascience, 3(2), 164-169.

Kolers, P. A. (1972). Aspects of Motion Perception. New York, Pergamon Press. 
Linden, D.E.J., Kallenbach, U., Heinecke, A., Singer, W., \& Goebel, R. (1999). The myth of upright vision. A psychophysical and functional imaging study of adaptation to inverting spectacles. Perception, 28, 469481.

Logothetis, N.K. Pauls, J., Oeltermann, A., Trinath, T., Augath, M. (2000). The relationship of LFPs, MUA, and SUA to the BOLD FMRI signal. Soc Neurosc Abstr.

Naumer, M., Milene, B., Grether, M., Muckli, L., Engel, A.K., Zanella, F.E., Singer, W., and Groebel, R. (2000). Threedimensional structure-from-motion activates shape-specific areas in the ventral visual processing stream. Neurolmage, 11, S691.

Sereno, M. I., Dale, A. M., Reppas, J. B., Kwong, K. K., Belliveau, J. W., Brady, T. J., Rosen, B. R. and Tootell, R. B. H. (1995). Borders of multiple visual areas in humans revealed by functional magnetic resonance imaging. Science. 268, 889-893.

Ungerleider, L. G. \& Mishkin, M. (1982). Two cortical visual systems. In D. J. Ingle, M. A. Goodale and R. J. W. Mansfield (eds.), Analysis of visual behavior. Cambridge, MA: MIT Press, pp. 549-586.

Wandell, B.A. (1999). Computational neuroimaging of human visual cortex. Annu Rev Neurosci., 22, 145-73. 